Article

\title{
Comparative Analysis of On- and Off-Grid Electrification: The Case of Two South Korean Islands
}

\author{
Heetae Kim ${ }^{1, *}$, Seoin Baek ${ }^{1,+}$, Kyu Ha Choi ${ }^{1,+}{ }^{,}$, Dojin Kim ${ }^{2,+}$, Seongmin Lee ${ }^{1,+}$, Dahill Kim ${ }^{1, \dagger}$ \\ and Hyun Joon Chang ${ }^{1,+}$ \\ 1 Graduate School of Innovation and Technology, KAIST, 2225, N5, 291 Daehak-ro, Yuseong-gu, \\ Daejeon 34141, Korea; wolihai87@kaist.ac.kr (S.B.); icingstar@kaist.ac.kr (K.H.C.); \\ urrth200@kaist.ac.kr (S.L.); dahill521@kaist.ac.kr (D.K.); hjc21c@kaist.ac.kr (H.J.C.) \\ 2 Graduate School of International Studies, Yonsei University, New Millennium Hall \#510, 50 Yonsei-Ro, \\ Seodaemun-gu, Seoul 03722, Korea; dojin@yonsei.ac.kr \\ * Correspondence: htya91@kaist.ac.kr; Tel.: +82-42-350-4902; Fax: +82-42-350-4340 \\ + All of the authors contributed equally to the work.
}

Academic Editor: Marc A. Rosen

Received: 10 November 2015; Accepted: 6 April 2016; Published: 11 April 2016

\begin{abstract}
South Korea's main industry is the manufacturing industry, and it requires stable energy. Korea heavily relies on importing oils to produce energy, thus efficient energy management is critical. This is why many renewable and smart energy policies and infrastructure planning are being set up currently. Supplying reliable and sustainable renewable energy to remote areas has especially been questioned; therefore, adopting sustainable and clean energy based on renewable resources cannot be delayed any more. This research examines the most economically, technologically and environmentally suitable energy grid of two South Korean Islands. Several hybrid energy system configurations that analyze and identify the optimal grid-connected and grid-independent hybrid power generation systems are simulated in this study. According to the results of the study, the optimal regionally detached power generation system was the wind-PV-battery-converter hybrid system. At the end of this paper, implications and limitations are discussed.
\end{abstract}

Keywords: renewable energy; HOMER simulation; on- and off-grid electrification; comparative analysis; hybrid energy system

\section{Introduction}

In current supply dominated paradigms, the efficient management of central grids, which work as a backbone system, has emerged as a crucial issue while demand management has gradually gained momentum [1]. This is why the economic feasibility analysis of on-/off-grids is needed to connect micro-grids with the central grid in a more effective way for increasing energy independency [2-4].

For this reason, many countries have implemented various micro-grid policies and programs for promoting the use of renewable energy [5-9]. Additionally, numerous global industrial complexes and university campuses also have adopted the micro-grid for their sustainable development as they have recognized the importance of an independent power system with a stable renewable energy supply [10-13].

Korea is the 11th biggest energy consumer and 9th biggest carbon dioxide emitter which is highly dependent on imported fossil fuel generation and nuclear power generation [14]. The main industry of Korea is the manufacturing industry, and the rapid development in national wealth has created a higher living standard for most of the general public. Thus, large and stable power generation is needed for fulfilling industrial and residential uses [15]. Therefore, the Korean government has understandably high motivation for seeking sustainable and efficient plans for renewable energy since Korea has limited natural energy resources $[1,16,17]$. 
In a bid to increase its renewable energy use, the Korean government is now actively promoting off-grid systems, based on single or hybrid renewable energy from the micro- to the large-scale [16,17]. The Jeolla province is an example of a micro-scale renewable energy off-grid system that has hosted the green energy independent island project in the Sangtae and Hatae Islands, which lack a stable power supply [18]. By supplying solar, wind renewables and energy storage systems (ESS), the green energy independent island project aims to construct an independent clean energy system; this project is expected to supply 35 households on two islands with renewable energy.

Alternatively, the Incheon metropolitan city has planned the Eco-island project, which is a large-scale off-grid system with five different areas: the Solar-Village, Wind-Village, Bio-Village, Tide-Village, and the Smart-Grid [19]. This project not only provides clean renewable energy to the neighboring islands but also supplies power to nearby industrial clusters and apartments. Through the Eco-island project, Incheon is set to become a global mecca of marine energy [19].

In this study, we aimed to identify the most economically, technologically, and environmentally suitable energy grid systems for Jindo-gun and Wando-gun by using its electric power consumption data, climate data (wind speed, radiation, location, etc.), and economic data (interest rate, useful life, etc.). This study employed the Hybrid Optimization Model for Electric Renewables (HOMER), which is a simulation tool and is widely used to plan optimal microgrids [20-23], to determine whether to maintain an on-grid energy system or to setup an independent off-grid system in Jin-do and Wand-do. After simulating and optimizing the hybrid system configured to compare, HOMER can be used for the sensitivity analysis to input values that should be analyzed more [24,25]. In the optimization step, HOMER simulates numerous different system configurations to find out the optimal solution that satisfies the technical restrictions at the lowest NPC (Net Present Cost). In the sensitivity analysis step, HOMER performs many optimization processes under inputs which researchers assumed to measure the effects of both uncertainties and changes of the input values [26]. The key difference between on- and off-grid systems is that off-grid refers to a system that is not connected to the main electrical system while an on-grid system is linked to the national electrical grid. Since both islands are located near the shore, losses from transmission and distribution might not exceed the expenses of setting up entirely new and independent off-grid systems. Thus, more accurate calculations are needed to measure the economic feasibility of both on- and off-grid systems in these islands.

\section{System Configuration}

Geographically, two islands analyzed in this research include both a coastline and scenic cliffs, and mountains, which provide excellent views and various kinds of seafood (Figure 1). Islands enjoy the warm climate that never gets too hot or too cold.

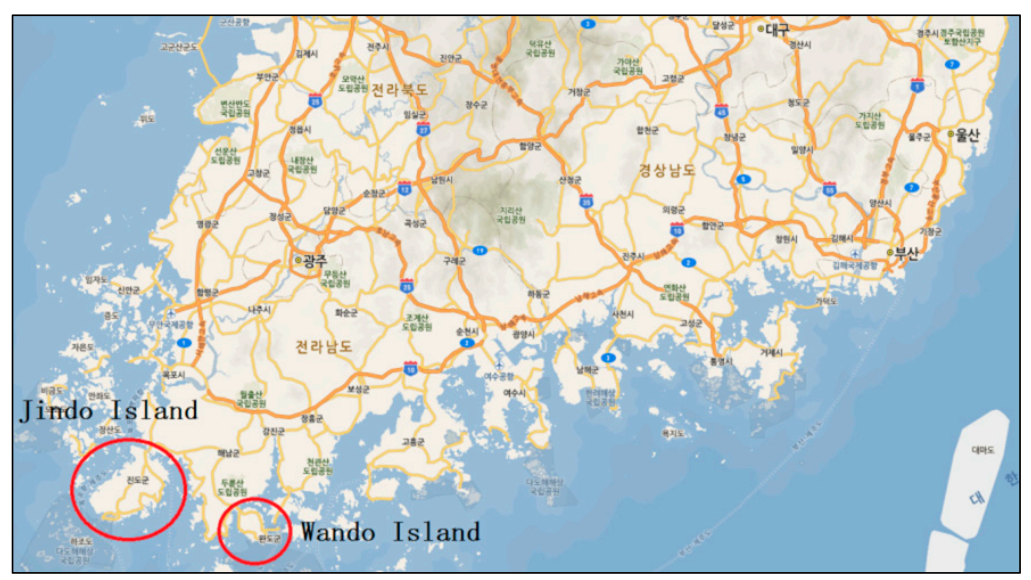

Figure 1. Geographic map of Jindo-gun and Wando-gun. 
Jindo-gun has approximately 33,000 residents and is located on the southwestern tip of the Korean peninsula; the center of Jindo-gun is $34^{\circ} 28^{\prime}$ latitude and $126^{\circ} 15^{\prime}$ longitude. The size of Jindo-gun is $363.16 \mathrm{~km}^{2}$, which is the third largest island in South Korea, and it has $306 \mathrm{~km}$ of shoreline. "Jindo-gun Bridge" has linked Jindo-gun and the mainland since 1984.

Wando-gun has approximately 22,000 residents and is located on the southwestern tip of the Korean peninsula; the center of Wando-gun is $34^{\circ} 19^{\prime}$ latitude and $126^{\circ} 45^{\prime}$ longitude. The size of Wando-gun is $88.57 \mathrm{~km}^{2}$, which is the 7th largest island in South Korea, and it has $105.9 \mathrm{~km}$ of shoreline. Wando-gun has been connected to the mainland by a bridge since 1967 .

This study analyzed and compared two islands, which were assumed to be independent on the central grid system (Figure 2).
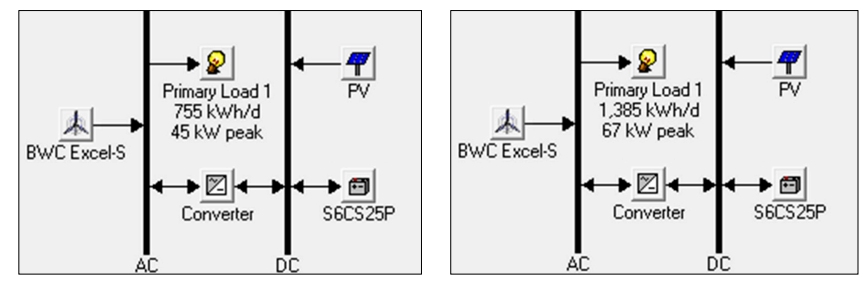

Figure 2. System configuration of the standalone hybrid system in Jindo-gun and Wando-gun.

\subsection{Load Profile}

Load profile data from the Jindo-gun Real Daily Demand List, which was published in 2013 by the Korea Electric Power Company, Inc. (KEPCO) (Seoul, Korea), were mainly analyzed for this study. The electric power supply of Jindo-gun is much higher in the winter and early spring than in the other seasons because of the weather conditions causing heavy power consumption.

As shown in Figure 3, the range of seasonal load values in Jindo-gun is higher from November to March, while May, June, and September have relatively lower power consumptions. Figure 4 shows the daily load profile of Jindo-gun, which can significantly affect lifetime or efficiency of the total system. The remarkable part of the profile is that the range of daily load values in Jindo-gun is comparatively lower during the day.

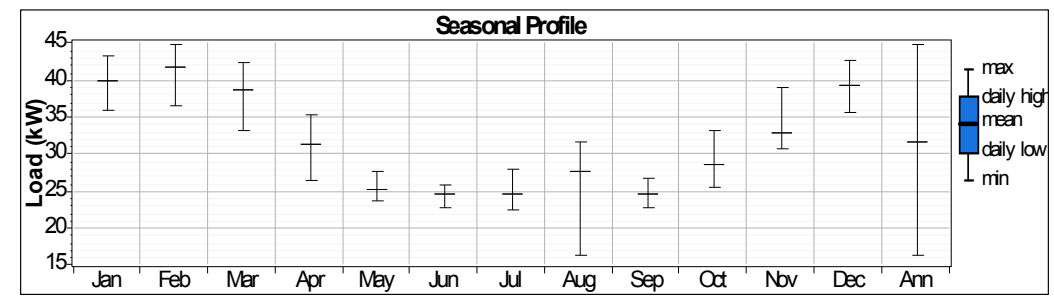

Figure 3. Seasonal load profile in Jindo-gun.

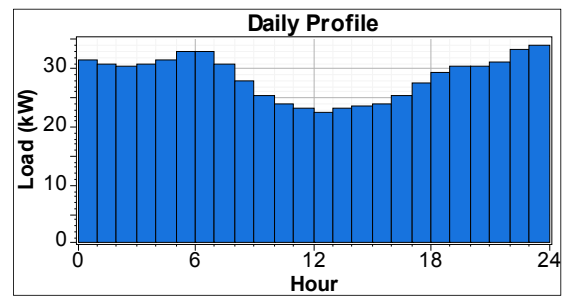

Figure 4. Daily load profile in Jindo-gun.

Data from the Wando-gun Real Daily Demand List, which were published in 2013 by the KEPCO were analyzed. The electric power supply of Wando-gun is higher during the winter and summer than in the other seasons given the surge in power usage owing to the weather conditions. 
Figure 5 shows that the mean and maximum loads in Wando-gun are low from May to July. Overall, the power consumption pattern is similar to that of Jindo-gun except for certain months. In particular, two load profiles in April, June, September, and December are noticeably different from each other. As shown in Figure 6, the range of daily load values in Windo-gun does not significantly differ all day.

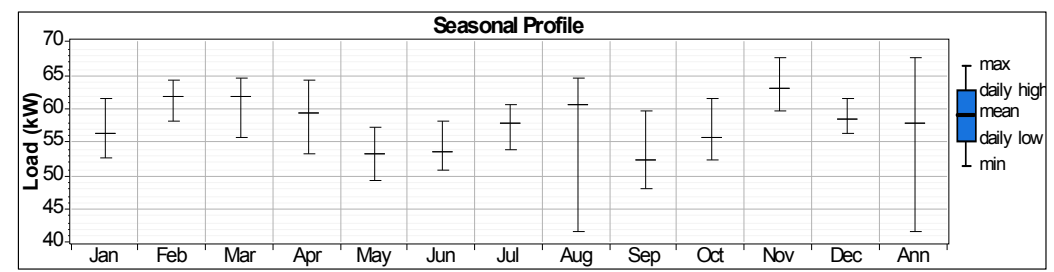

Figure 5. Seasonal load profile in Wando-gun.

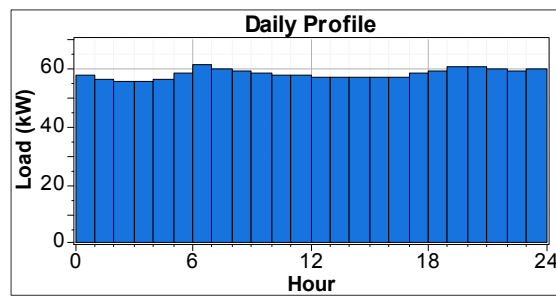

Figure 6. Daily load profile in Wando-gun.

In this study, the total load of both areas, Jindo-gun and Wando-gun, were analyzed in $\mathrm{kWh}$ instead of MWh to enhance the exactness of the research results [2,4].

\subsection{Renewable Energy Resources}

\subsubsection{Wind Energy Resources}

The monthly average wind speed values for a year used in this study were obtained from both the Korea Meteorological Administration (KMA) and the NASA Surface Meteorology and Solar Energy using the longitude and latitude of Jindo-gun $[27,28]$. Additional parameters include the Weibull coefficient, $1 \mathrm{~h}$ autocorrelation factor, diurnal pattern strength, and hour of peak wind speed, and each value is $2,0.85,0.25$, and 15 , respectively. These parameters, which are provided by HOMER, are used repeatedly in previous research [2].

The value of the wind speed in Wando-gun is less than that for the Jindo-gun data. Figures 7 and 8 compare the wind energy resources in Wando-gun with that of the Jindo-gun. The data clearly show that Wando-gun has comparatively weaker wind power than Jindo-gun.

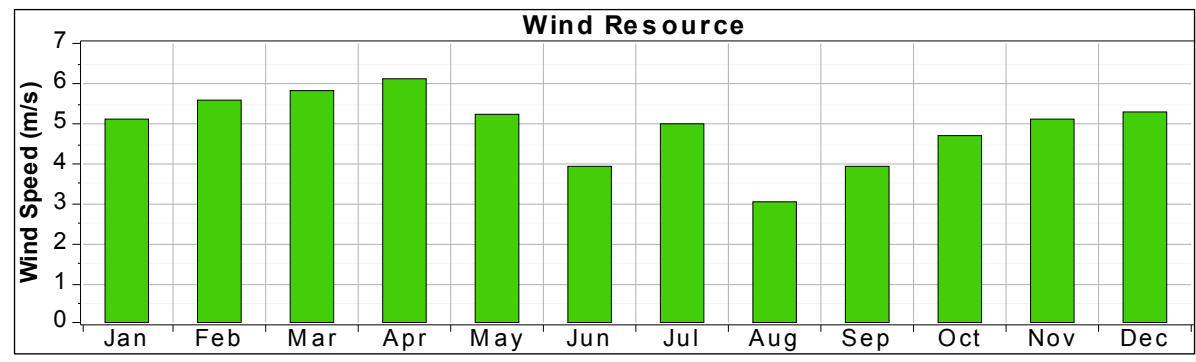

Figure 7. Wind resources in Jindo-gun. 


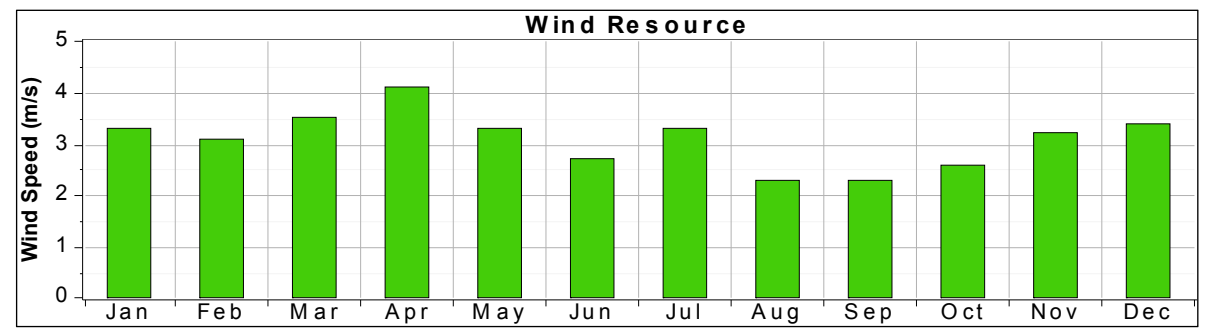

Figure 8. Wind resources in Wando-gun.

\subsubsection{Solar Energy Resources}

Solar energy, which is becoming more fascinating and being globally used as a counterplan to conventional energy [29] and does not emit greenhouse gases, is the crucial topic of renewable energy [30]. This study used radiation and a monthly clearness index, obtained from the KMA and NASA Surface Meteorology and Solar Energy [27], that are based on the geographic information, latitude and longitude, of Jindo-gun and Wando-gun. According to the NASA data, two areas produce the same solar energy as calculated by the monthly clearness index. Unlike for wind energy, sensitivity analysis was not conducted for this resource. The average level of solar radiation in the research object region is greater than that of South Korea (Figure 9).

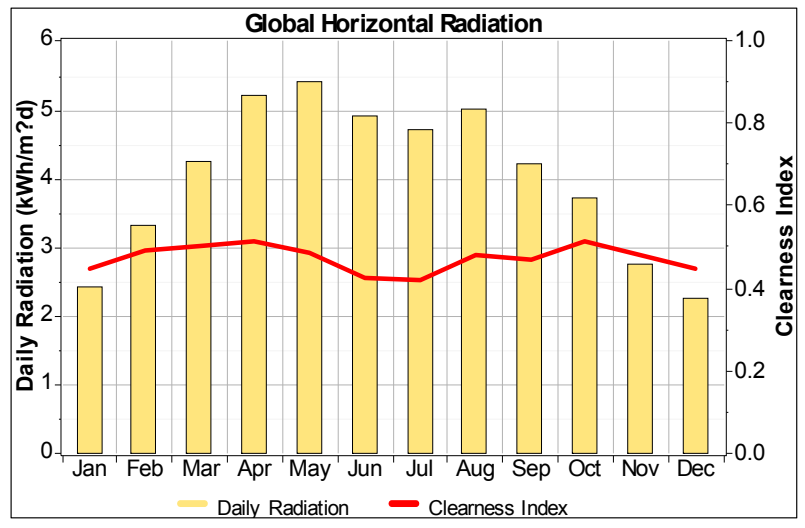

Figure 9. Global horizontal radiation.

\subsection{Background Economic Rationale}

Most of the renewable energy projects are long-term developments, as governments generally try to increase the harnessing of renewable energy gradually. In the existing studies, projects last between 15 to 40 years. Accordingly, this study also set the project duration as 20 years. Based on the information published by the Bank of Korea [31], the real annual interest rate was calculated as $1.16 \%$ using the Fisher equation.

\subsection{Renewable Energy Generation Systems}

In this study, we assumed the initial installation costs of photovoltaic array, the replacement costs, and the yearly operation and maintenance (O\&M) costs per $1 \mathrm{~kW}$ as $\$ 2730, \$ 2730$, and $\$ 27$, respectively. These values were calculated using a previous reference, which is a report issued in 2011 by the Intergovernmental Panel on Climate Change (IPCC) [32]. In the previous research, the annual O\&M costs of PV panels were assumed to be approaching 0 [33]. We also assumed the lifetime of a PV array as 25 years. A derating factor, which this study assumed as 0.8 , was also required to input technical details.

This study assumed that all panels were fixed and tilted at the value of latitude of each area. The reflectance was assumed as $20 \%$, while the sizes of the simulation-values of the applied PV panels 
were $0,50,75,100,125,150,170,175,180$, and $200 \mathrm{~kW}$ in Jindo-gun. Furthermore, the sizes of the simulation-values applied to the PV panels were $0,325,350,375,400,625,650,675$, and $700 \mathrm{~kW}$ in Wando-gun.

In this study, we selected the BWC Excel-S $10 \mathrm{~kW}$ AC model (Bergey Windpower, Oklahoma, OK, USA) as the wind turbine model to simplify the simulation. Considering the exchange rate, we assumed the initial installation costs, replacement costs, and annual O\&M costs of the BWC Excel-s model as $\$ 15,041, \$ 15,041$, and $\$ 92$, respectively. These costs were also based on the report published in 2011 by the IPCC [32], as well as the recommendations of interview results with experts from Korea South-East Power and the Korea Electric Power Corporation Research Institute. We also assumed the lifetime of the BWC Excel-s model and the height of the hub as 15 years and $30 \mathrm{~m}$, which have been used the most in previous research, respectively. The numbers of simulation-value wind turbines applied were $0,10,12,15,17,20,70,75,80$, and 85 in Jindo-gun; furthermore, the numbers of simulation-value wind turbines applied were 0, 20, 22, 25, 27, and 30 in Wando-gun. Since Wando-gun has less wind energy resources, it does not need a larger number of wind turbines despite its higher electricity load.

Based on the state-of-the-art study on hybrid energy systems, which need DC-AC power conversion, we assumed the initial installation, replacement, and annual O\&M costs as $\$ 72,926$, $\$ 72,926$, and $\$ 912$ per $100 \mathrm{~kW}$, respectively [34]. The lifetime of the converter, the capacity of the rectifier, and the efficiency of a converter were set as 15 years, $90 \%$, and $85 \%$, respectively. In both areas, the sizes of the converters were considered to be $0,40,50,55,60,65,70,80,85,90$, and $95 \mathrm{~kW}$.

Batteries always have quite a high expense, which causes economic feasibility of hybrid energy systems to be below professionals' expectations. However, batteries are necessary to reduce instabilities of electric power flow, to improve efficiency of the hybrid energy system, and to supply stable electric energy [35]. Batteries are the most difficult component to model. Thus, we use sensitivity analysis to select both the Surrette 6CS25P battery (6.94 kWh) (Rolls/Surrette, Springhill, NS, Canada) and the Hoppecke 20 OpzS2500 battery (5 KWh) (Hoppecke, New Jersey, NY, USA), which are widely used for hybrid energy system analysis in this study, as a storage system to analyze and simulate the optimal hybrid energy system [33,35-37].

In this study, we assumed the initial costs of installing the battery, the replacement cost, and the annual O\&M costs as $\$ 228, \$ 228$, and $\$ 1$ per 1 Surrette 6CS25P; $\$ 1500, \$ 1500$, and $\$ 10$ per 1 Hoppecke 20 OpzS2500, respectively. We also assumed that the initial status of battery was fully charged. The HOMER simulation applied used the kinetic battery model. This model is named as a "two-tank system", which means one battery pack can be recharged for consumption at any time, whereas the other battery pack can be discharged with a constant electric current [33]. For the sensitivity analysis of the battery in Jindo-gun, cases with a total of $0,55,60,65,85,90$, and 95 batteries are implemented. Similarly, $0,40,50,60,70,80$, and 90 batteries cases were conducted for the sensitivity analysis for Wando-gun.

\subsection{Grids}

On-grid electrification, which is called grid-connected, means that the power system connects to a central grid. The grid can supply the load, and the power system can also sell the extra generated electric power to the grid. Off-grid electrification, on the other hand, is remote from other power systems. This is known as a stand-alone power generation system and is very sensitive to the power demand. Thus, the off-grid system usually requires additional power sources, such as diesel generators or the ESS.

The NPC of grid extension has two main elements. One is the NPC of buying electric power from the central grid over the project period. The other is the NPC of extension of the grid, which is equal to the NPC per $\mathrm{km}$ times the distance between two areas in $\mathrm{km}$. If the electric power grid required expansion, then selecting the cost of the grid extension should be assumed to cost $\$ 18,232 / \mathrm{km}[2]$. This study considered that the cost of electricity (COE) of the grid is $\$ 0.09 / \mathrm{kW}$ according to the SMP 
(System Marginal Price) information system of electric power exchange from the power statistics, which is officially provided by Korea Power eXchange (KPX).

In contrast, when selling the extra electric power to the central grid, the weighting and renewable energy certificates (REC) of the solar and wind energies must be considered when calculating costs. Additionally, the average price of solar and wind power in March 2013 and the fact that the average price of a solar REC is higher than that of a wind REC are two aspects to consider carefully. Finally, this study assumed the price of electricity sales as $\$ 0.14 / \mathrm{kWh}$. The profitability of the renewable energy industry of Jeolla province is still low due to several regional constraints. However, the profitability is expected to expand given the policies being introduced soon.

\section{Optimization and Simulation Results}

If hybrid systems were configured only by the renewable energy generation, then systems could be analyzed with the concepts of NPC and COE to determine whether they are economically feasible for investments. HOMER is an optimizing tool for the hybrid system including renewable energies; thus, the NPC is the most important economic indicator in this HOMER research.

\subsection{Jindo-Gun: Optimized PV-Wind-Battery-Converter Hybrid Systems}

The optimized on-grid system was analyzed for a case in which the system was located within $22.4 \mathrm{~km}$ limits. The on-grid system was more feasible than an independent system. Integrating the system with the main land grid would be less feasible after the addition of new submarine cables for Jindo-gun since the land system is already connected to the grid. If they were not connected, then a dependent hybrid system would be more feasible since the distance between Jindo-gun and Mokpo-si is $39.5 \mathrm{~km}$, which is further than $22.4 \mathrm{~km}$ (Figure 10).

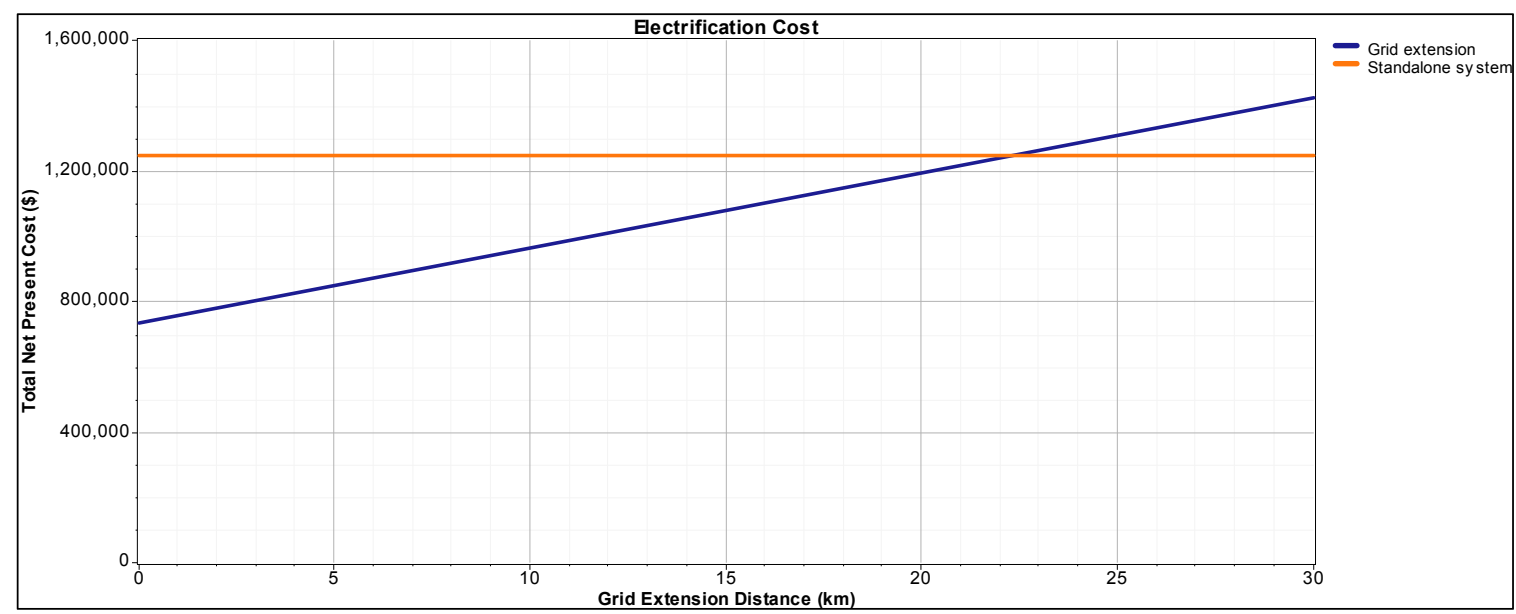

Figure 10. Electrification cost comparison in Jindo-gun.

Jindo-gun is already connected to the power grid, which means that it would be more economically feasible to purchase power from the grid than to construct a stand-alone hybrid system. However, since the distance between Jindo-gun and Mokpo is further than the marginal conditions, the independent hybrid system proposed should be applied in Jindo-gun in order to transform it into a low-carbon island. When this optimal hybrid system is applied to the island region at a distance closer than $22.4 \mathrm{~km}$ from the grid of Southeast Asia and Africa, with similar load profiles and environmental conditions at the same period, then the grid-connected hybrid system would be more economically feasible.

Using 15 wind turbines, a PV capacity of $175 \mathrm{~kW}, 700$ Surrette 6CS25P batteries (4.858 MWh), and a converter capacity of $55 \mathrm{~kW}$, the hybrid system was configured in conformity with the optimized results obtained from the HOMER simulations. This hybrid system was expected to produce 
217,810 kWh/year and 251,255 kWh/year by PV array and wind turbines, respectively, and also consume $275,469 \mathrm{kWh} /$ year by AC primary load.

The NPC of this system was $\$ 1,247,399$ while the COE was $\$ 0.254$ and the operating cost was $\$ 14,381$ per year with $100 \%$ of the total power generation from renewable energy, including PV and wind turbines (Table 1). According to the simulation results, $46 \%$ of the power generation was generated by solar energy and $54 \%$ from wind power (Figure 11).

Table 1. Cost structure of the Jindo-gun hybrid system.

\begin{tabular}{cccccc}
\hline Component & Capital (\$) & Replacement (\$) & O\&M * (\$) & Salvage (\$) & Total (\$) \\
\hline PV & 525,000 & 0 & 93,417 & $-83,701$ & 534,716 \\
BWC Excel-S & 247,500 & 208,800 & 26,691 & $-131,530$ & 351,461 \\
Surrette 6CS25P & 175,000 & 152,744 & 12,456 & $-46,501$ & 293,699 \\
Converter & 44,000 & 37,120 & 9787 & $-23,383$ & 67,523 \\
System & 991,500 & 398,664 & 142,350 & $-285,115$ & $1,247,399$ \\
\hline
\end{tabular}

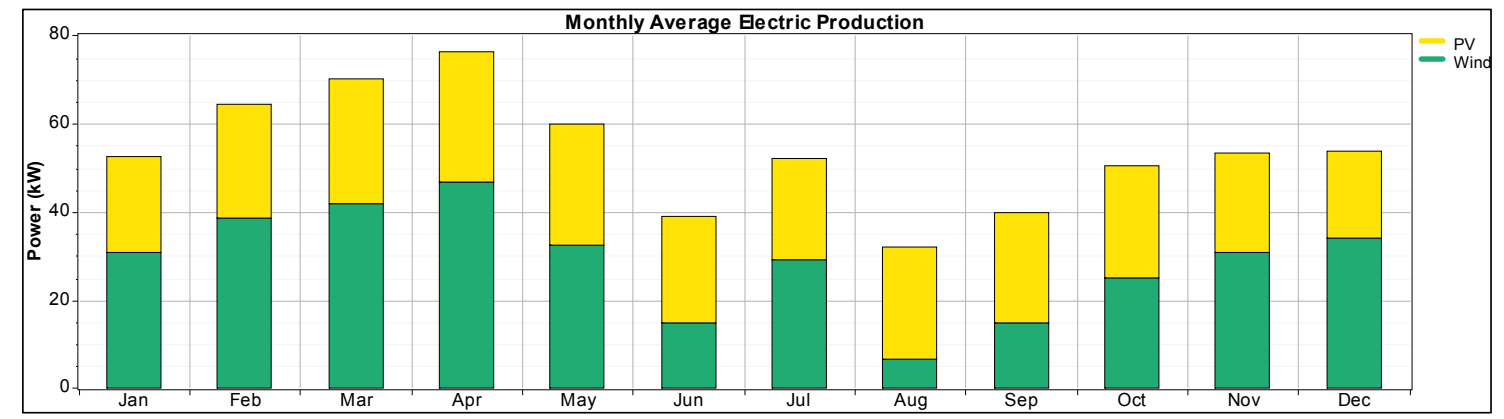

Figure 11. Monthly average electricity production in Jindo-gun.

\subsection{Wando-Gun: Optimized PV-Wind-Battery-Converter Hybrid Systems}

The stand-alone system was analyzed for a case in which the system was located within $38.3 \mathrm{~km}$ limits. The stand-alone system was more feasible than an independent system. Integrating the system with the mainland system would be more feasible with the addition of a submarine cable for Wando-gun since the land system is already connected to the grid. If they were not connected, then the dependent hybrid system would be less feasible since the distance between Wando-gun and Hanam-si is $24.3 \mathrm{~km}$, which is less than $38.3 \mathrm{~km}$ (Figure 12).

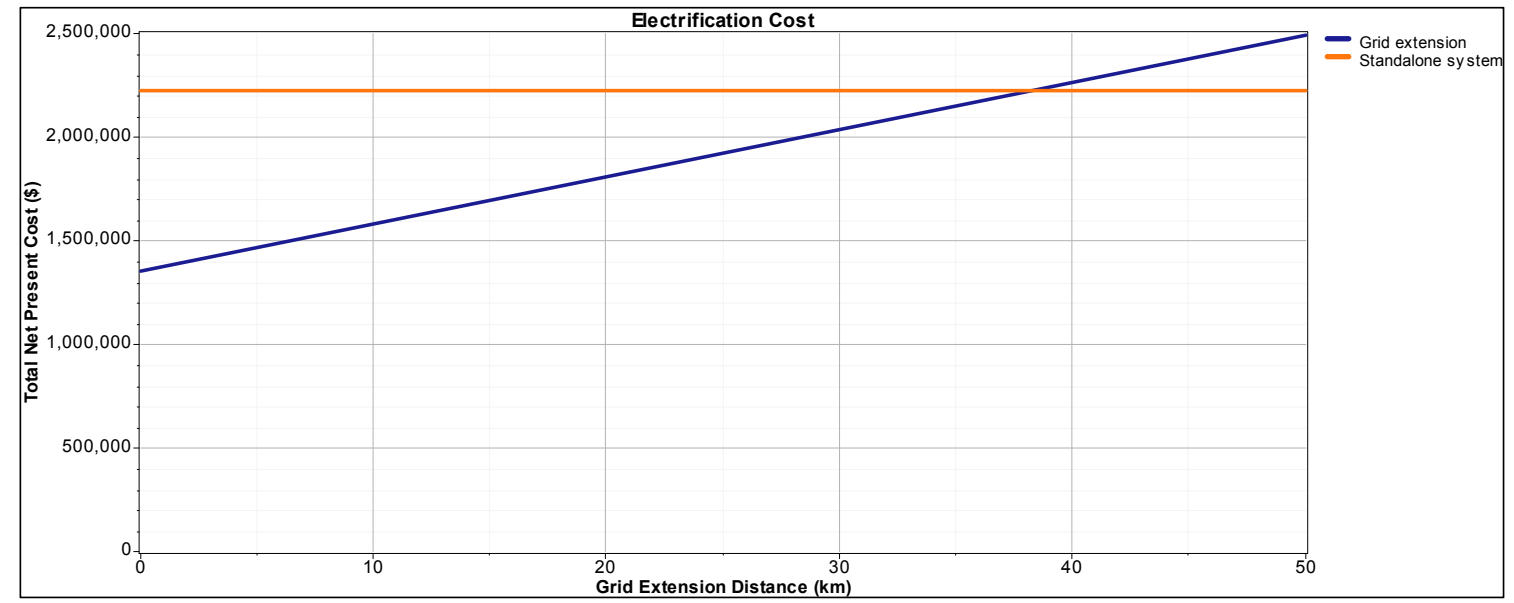

Figure 12. Electrification cost comparison in Wando-gun. 
Wando-gun is already connected to the power grid. Additionally, the distance between Wando-gun and Hanam is shorter than the marginal conditions. Thus, the connected grid system would always be more economically feasible. However, when this optimal hybrid system is applied to the island region at distances further than $38.3 \mathrm{~km}$ from the grid of Southeast Asia and Africa, given similar load profiles and environmental conditions at the same time period, then the independent hybrid system would be more economically feasible.

Using 20 wind turbines, a PV capacity of $375 \mathrm{~kW}, 1250$ Surrette 6CS25P batteries (8.675 MWh), and a converter capacity of $70 \mathrm{~kW}$, the hybrid system was configured in conformity with the optimized results obtained from the HOMER simulations. The optimal hybrid system, which we suggested, was expected to produce $466,737 \mathrm{kWh} /$ year and 332,090 kWh/year by PV array and wind turbines, respectively, and also consume $505,499 \mathrm{kWh}$ /year by AC primary load.

The NPC of this system was $\$ 2,224,835$ while the COE was $\$ 0.247$ and the operating cost was $\$ 22,555$ per year with $100 \%$ of the total power generation from renewable energy, including PV and wind turbine (Table 2). Of the power generated, $58 \%$ was from solar energy and $42 \%$ from wind power (Figure 13).

Table 2. Cost structure of the Wando-gun hybrid system.

\begin{tabular}{cccccc}
\hline Component & Capital (\$) & Replacement (\$) & O\&M * (\$) & Salvage (\$) & Total (\$) \\
\hline PV & $1,125,000$ & 0 & 200,179 & $-179,359$ & $1,145,820$ \\
BWC Excel-S & 330,000 & 278,400 & 35,587 & $-175,373$ & 468,614 \\
Surrette 6CS25P & 312,500 & 272,756 & 22,242 & $-83,037$ & 524,462 \\
Converter & 56,000 & 47,244 & 12,456 & $-29,760$ & 85,939 \\
System & $1,823,500$ & 598,400 & 270,464 & $-467,530$ & $2,224,835$ \\
\hline
\end{tabular}

${ }^{*}$ Operation and maintenance costs.

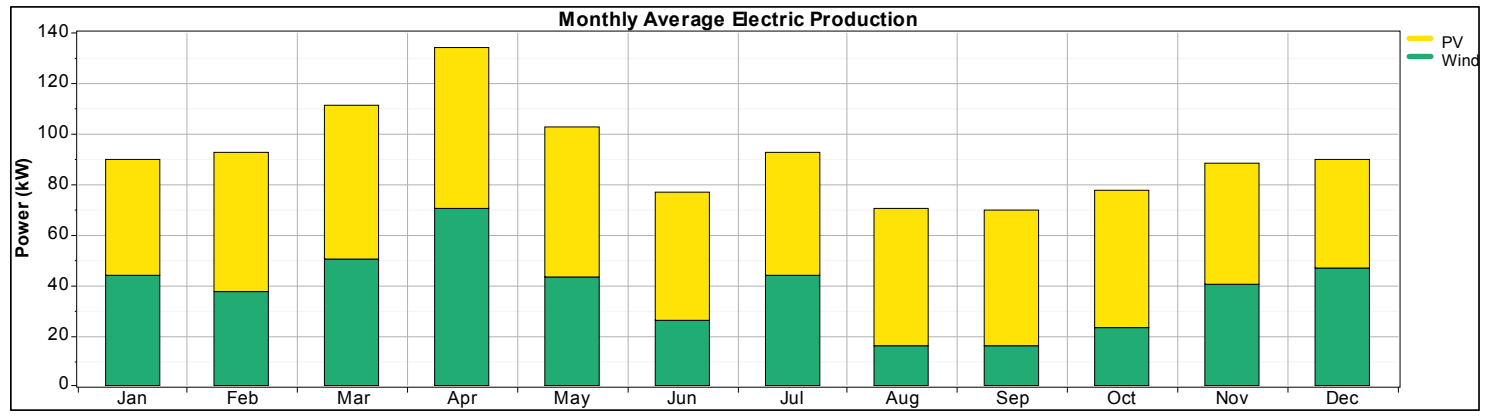

Figure 13. Monthly average electric production in Wando-gun.

No carbon dioxide was emitted in two systems. Therefore, each optimal hybrid system on two islands would become more economically feasible when a carbon trading system is activated.

\section{Conclusions}

The main purpose of the study is to simulate several hybrid systems to specifically analyze and identify the optimal systems among grid-connected and grid-independent hybrid power generation systems. The optimal standalone power generation system was the wind turbine-PV-battery-converter hybrid system. The hybrid system consisting of photovoltaic and wind power was the most practical option for the Republic of Korea, especially in Jindo-gun and Wando-gun [17], among the various options, such as solar, wind, small hydro, micro-turbine, fuel cell, and bio-renewable energy sources. 
A stable supply of energy is no longer an option in the contemporary world. Economic, social, and cultural activities all highly depend on electricity; we simply cannot live without it. While the demand of electricity has increased constantly, various difficulties have existed with regard to the supply. Although three conventional resources (namely, fossil fuel, nuclear, and hydropower) have provided energies with relatively cheap costs, they have also caused a significant amount of environmental degradation. Micro-grid and optimal hybrid systems can increase flexibility and efficiency of the power management system when combined with renewable energy. Micro-grids have been studied and developed in order to optimize their use in regions that require an independent power supply system. The economic feasibility and sensitivity analysis for the various elements of the micro-grid are necessary before the full-scale introduction. Both analyses should focus on the development of related technologies; however, it is necessary to promote policies based on research results that determine whether the policies would be economically and environmentally feasible. Therefore, the preliminary rationale of this study reveals quite promising results. This study focused on deriving the most optimized hybrid system consisting of renewable energy and other devices. Furthermore, this study compared the economic feasibility of connected and independent micro-grids.

The results presented in this paper should be carefully considered when making policies such as a green island policy in the near future or when carrying out the microgrid island project in Jeolla province, which aims to ensure self-sustaining energy. Currently, Jeolla province is planning various micro-grid islands, which are energy self-sufficient and 100\% sourced by renewable energy. The results of this study indicate that these goals can be achieved if they agree to increase the cost of electricity. Therefore, policy makers should ensure sufficient power output to increase the power reserve margin to simultaneously achieve electricity stability, and high economic and environmental performance. However, these goals require related supporting policies or subsidies to activate the domestic renewable energy market as it is still relying heavily on governmental support [38,39]. Although the wind energy is sufficient in Jindo-gun and Wando-gun, a strong market revitalization strategy and plan still need to be developed.

A limitation of this study is the fact that the cost of purchasing land and the direction/distance between the turbines given the wind interference was not considered although the cost of the equipment itself was included when designing the solar and wind power systems. Second, the analysis could be strengthened enough with sensitivity analysis. Even if the solution found is mathematically optimal for the input data, it may be that there are other solutions that would not cost much more than the optimal hybrid system that we supposed in this study. Third, this paper could be a much more valuable if it were somewhat extended and deepened to show, through this case study, how other regions might be able to adopt similar systems. Finally, this study simulates systems with HOMER, a program developed by the National Renewable Energy Laboratory (NREL) for energy-mix optimization research. HOMER is a highly analytic tool that reliably provides simulation results that can help governments or companies to start the renewable energy generation business. HOMER is an advantageous method when modeling the use of solar energy, especially the photovoltaic array. Thus, the system that our study supposes is mathematically optimal. However, it still contains some uncertainties when modeling wind power simulations at one-hour intervals and distinguishing the loads between mandatory and secondary. There may be other optimal solution which is more cost effective than the ones founded by HOMER simulation.

Given the multiple limitations that we mentioned, future studies should consider some varying economic values by introducing the RPS (Renewable Portfolio Standard) and carbon emissions trading systems. Moreover, learning curves and economies of scale, which are also related fields of energy research should be reflected, as these factors could decrease the total cost of renewable energy systems over time. Learning curves have been used to monitor the changes in performance and costs in the renewable energy area [40-42]. Thus, more accurate assessment on the economic feasibility of the hybrid system would be possible. Future studies should conduct analysis that includes precise evaluation of the cost of land with the consideration of each area. Second, we can double check the 
research results with two or more methodologies in the future study to strengthen the research method. Then, we will be able to verify our research results more accurately. Finally, according to the results of the study conducted by the LG Economic Research Institute, the lifespan of the usual ESS as a power device may be greater than 20 years [43]. However, a somewhat conservative value of 15 years was considered in this study. This means that economic feasibility can be sufficiently increased in accordance with the technical level of development in the near future. It is no longer sufficient to only have a smart grid to manage both supply and demand. Since South Korea is in the stage of promoting the widespread use of renewable energy, the role of ESS is expected to become more important in the near future.

Author Contributions: Heetae Kim analyzed the data and completed the first draft; Seoin Baek, Kyu Ha Choi, Dojin Kim, Seongmin Lee, and Dahill Kim wrote specific parts and revised the paper; and Hyun Joon Chang reviewed and revised the final version of paper.

Conflicts of Interest: The authors declare no conflict of interest.

\section{References}

1. Kim, H.; Shin, E.; Chung, W. Energy demand and supply, energy policies, and energy security in the Republic of Korea. Energy Policy 2011, 39, 6882-6897. [CrossRef]

2. Kim, H.; Baek, S.; Park, E.; Chang, H.J. Optimal green energy management in Jeju, South Korea-On-grid and off-grid electrification. Renew. Energy 2014, 69, 123-133. [CrossRef]

3. Yoo, K.; Park, E.; Kim, H.; Ohm, J.Y.; Yang, T.; Kim, K.J.; del Pobil, A.P. Optimized Renewable and Sustainable Electricity Generation Systems for Ulleungdo Island in South Korea. Sustainability 2014, 6, 7883-7893. [CrossRef]

4. Baek, S.; Kim, H.; Chang, H.J. Optimal Hybrid Renewable Power System for an Emerging Island of South Korea: The Case of Yeongjong Island. Sustainability 2015, 7, 13985-14001. [CrossRef]

5. Ayoub, N.; Yuji, N. Governmental intervention approaches to promote renewable energies-Special emphasis on Japanese feed-in tariff. Energy Policy 2012, 43, 191-201. [CrossRef]

6. Hirschl, B. International renewable energy policy between marginalization and initial approaches. Energy Policy 2009, 37, 4407-4416. [CrossRef]

7. Kitzing, L.; Mitchell, C.; Morthorst, P.E. Renewable energy policies in Europe: Converging or diverging? Energy Policy 2012, 51, 192-201. [CrossRef]

8. Moosavian, S.M.; Rahim, N.A.; Selvaraj, J.; Solangi, K.H. Energy policy to promote photovoltaic generation. Renew. Sustain. Energy Rev. 2013, 25, 44-58. [CrossRef]

9. Di, D.V.; Favuzza, S.; La Cascia, D.; Massaro, F.; Zizzo, G. Critical assessment of support for the evolution of photovoltaics and feed-in tariff(s) in Italy. Sustain Energy Technol. Assess. 2015, 9, 95-104. [CrossRef]

10. Jenkins, N.; Allan, R.; Crossley, P.; Kirschen, D.; Strbac, G. Embedded Generation, 1st ed.; IEEE Power and Energy Series; The Institution of Electrical Engineers: London, UK, 2000; pp. 189-251.

11. Asano, H.; Hatziargyriou, N.; Iravani, R.; Marnay, C. Microgrids: An overview of ongoing research, development, and demonstration projects. IEEE Power Energy Mag. 2007, 5, 78-94.

12. Lidula, N.W.A.; Rajapakse, A.D. Microgrids research: A review of experimental microgrids and test systems. Renew. Sustain. Energy Rev. 2011, 15, 186-202. [CrossRef]

13. Bracco, S.; Delfino, F.; Pampararo, F.; Robba, M.; Rossi, M. The University of Genoa smart polygeneration microgrid test-bed facility: The overall system, the technologies and the research challenges. Renew. Sustain. Energy Rev. 2013, 18, 442-459. [CrossRef]

14. International Energy Agency (IEA). World Energy Outlook; International Energy Agency: Paris, France, 2013.

15. Ryu, J.C.; Lee, S.K. Korea's Perspective on Energy and Economic Cooperation in Northeast and Central Asia. In Proceedings of the International Symposium on Energy Resources Cooperation and Corporate Strategy in Northeast and Central Asia, Seoul, Korea, 3 July 2008.

16. Lee, T.; Lee, T.; Lee, Y. An experiment for urban energy autonomy in Seoul: The One "Less" Nuclear Power Plant policy. Energy Policy 2014, 74, 311-318. [CrossRef]

17. Kim, H.; Park, E.; Kwon, S.J.; Ohm, J.Y.; Chang, H.J. An integrated adoption model of solar energy technologies in South Korea. Renew. Energy 2014, 66, 523-531. [CrossRef] 
18. Wando-County. Available online: http://www.wando.go.kr/ (accessed on 5 November 2015).

19. Incheon Metropolitan City. Available online: http://www.incheon.go.kr/index.do (accessed on 5 November 2015).

20. Lambert, T.; Gilman, P.; Lilienthal, P. Micropower system modeling with HOMER. Integr. Altern. Sources Energy 2006, 1, 379-418.

21. Sinha, S.; Chandel, S.S. Review of software tools for hybrid renewable energy systems. Renew. Sustain. Energy Rev. 2014, 32, 192-205. [CrossRef]

22. Hafez, O.; Bhattacharya, K. Optimal planning and design of a renewable energy based supply system for microgrids. Renew. Energy 2012, 45, 7-15. [CrossRef]

23. Bahramara, S.; Jafari, F.; Rahimi-Kian, A.; Lesani, H. Planning of a Grid-connected Smart Micro-power system. In Proceedings of the 2012 IEEE Innovative Smart Grid Technologies-Asia (ISGT Asia), Tianjin, China, 21-24 May 2012.

24. NASA. Earth Data Atmospheric Science Data Center. Available online: https://eosweb.larc.nasa.gov (accessed on 5 November 2015).

25. Katsigiannis, Y.A.; Georgilakis, P.S.; Karapidakis, E.S. Genetic Algorithm Solution to Optimal Sizing Problem of Small Autonomous Hybrid Power Systems. In Artificial Intelligence: Theories, Models and Applications, Proceedings of 6th Hellenic Conference on AI, SETN 2010, Athens, Greece, 4-7 May 2010; pp. 327-332.

26. Connolly, D.; Lund, H.; Mathiesen, B.V.; Leahy, M. A review of computer tools for analysing the integration of renewable energy into various energy systems. Appl. Energy 2010, 87, 1059-1082. [CrossRef]

27. Bjelic, I.B.; Rajaković, N.; Ćosić, B.; Duić, N. Increasing wind power penetration into the existing Serbian energy system. Energy 2013, 57, 30-37. [CrossRef]

28. KMA. Annual climatological report 2013, Korea Meteorological Administration. Available online: http:/ / www.kma.go.kr/weather/observation/data_monthly.jsp (accessed on 22 July 2015).

29. Nema, P.; Nema, R.K.; Rangnekar, S. A current and future state of art development of hybrid energy system using wind and PV-solar: A review. Renew. Sustain. Energy Rev. 2009, 13, 2096-2103. [CrossRef]

30. Lee, M. Global trends and implication for the PV industry. Korea Dev. Bank J. 2008, 631, 65-98.

31. The Bank of Korea Monetary Policy. Available online: http://www.bok.or.kr/baserate/baserateList.action? menuNavild=33 (accessed on 22 July 2015).

32. Karakoulidis, K.; Mavridis, K.; Bandekas, D.V.; Adoniadis, P.; Potolias, C.; Vordos, N. Techno-economic analysis of a stand-alone hybrid photo voltaic-diesel-battery-fuel cell power system. Renew. Energy 2011, 36, 2238-2244. [CrossRef]

33. Liu, G.; Rasul, M.G.; Amanullah, M.T.O.; Khan, M.M.K. Techno-economic simulation and optimization of residential grid-connected PV system for the Queensland climate. Renew. Energy 2012, 45, 146-155. [CrossRef]

34. Kusakana, K.; Vermaak, H.J. Hybrid renewable power systems for mobile telephony base stations in developing countries. Renew. Energy 2013, 51, 419-425. [CrossRef]

35. Ashourian, M.H.; Cherati, S.M.; Zin, A.M.; Niknam, N.; Mokhtar, A.S.; Anwari, M. Optimal green energy management for island resorts in Malaysia. Renew. Energy 2013, 51, 36-45. [CrossRef]

36. Asrari, A.; Ghasemi, A.; Javidi, M.H. Economic evaluation of hybrid renewable energy systems for rural electrification in Iran-A case study. Renew. Sustain. Energy Rev. 2012, 16, 3123-3130. [CrossRef]

37. Demiroren, A.; Yilmaz, U. Analysis of change in electric energy cost with using renewable energy sources in Gökceada, Turkey: An island example. Renew. Sustain. Energy Rev. 2010, 14, 323-333. [CrossRef]

38. Kang, H. The emerging PV industry. In CEO Information; Samsung Economic Research Institute: Seoul, Korea, 2007; p. 616.

39. Ministry of Knowledge Economy (MKE). New and Renewable Energy White Paper 2008 (in Korea); Ministry of Knowledge Economy: Gwacheon, Korea, 2008.

40. Duke, R.D. Clean energy technology buydowns: Economic theory analytic tolls, and the photovoltaics case. Ph.D. Thesis, Princeton University, Princeton, NJ, USA, November 2002.

41. Schaeffer, G.J.; Seebregts, A.J.; Beurskens, L.W.M.; de Moor, H.H.C.; Alsema, E.A.; Sark, W. Learning from the Sun. Analysis of the Use of Experience Curves for Energy Policy Purposes: The Case of Photovoltaic Power; Final Report of the PHOTEX Projects, ECn-C-4-035; Energy Research Center of the Netherlands: Petten, The Netherlands, 2004. 
42. Nemet, G.F. Beyond the learning curve: Factors influencing cost reductions in photovoltaics. Energy Policy 2005, 34, 3218-3232. [CrossRef]

43. LGERI Business Insight Weekly Focus. Available online: http://www.lgeri.com/uploadFiles/ko/pdf/ind/ LGBI1276-27_20131118094658.pdf (accessed on 5 November 2015).

(c) 2016 by the authors; licensee MDPI, Basel, Switzerland. This article is an open access article distributed under the terms and conditions of the Creative Commons Attribution (CC-BY) license (http://creativecommons.org/licenses/by/4.0/). 